\title{
Upgrading of Heavy Oil from the San Joaquin Valley of California by Aqueous Pyrolysis
}

\author{
John G. Reynolds \\ Ann M. Murray \\ Eric V. Nuxoll \\ Glenn A. Fox
}

RECEMED

JUL 221203

OSTI

October 1, 1995

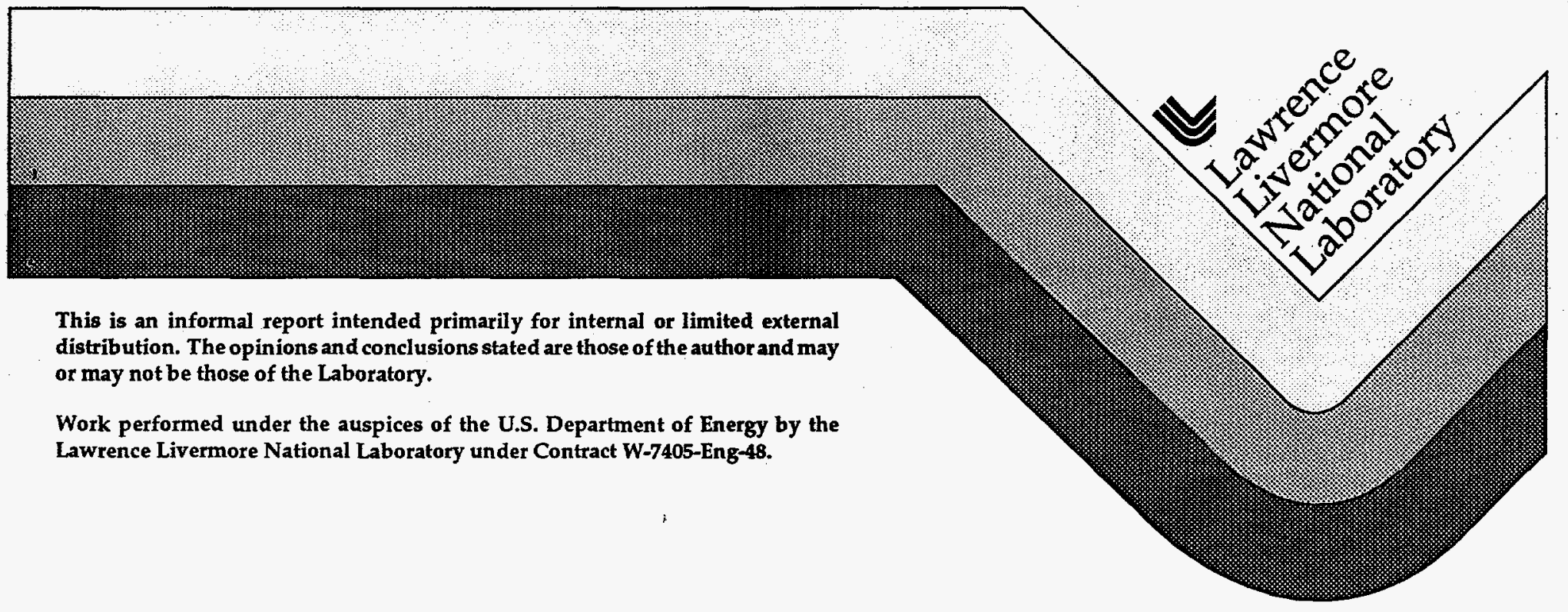




\section{DISCLAIMER}

This document was prepared as an account of work sponsored by an agency of the United States Government. Neither the United States Government nor the University of California nor any of their employees, makes any warranty, express or implied, or assumes any legal liability or responsibility for the accuracy, completeness, or usefulness of any information, apparatus, product, or process disclosed, or represents that its use would not infringe privately owned rights. Reference herein to any specific commercial product, process, or service by trade name, trademark, manufacturer, or otherwise, does not necessarily constitute or imply its endorsement, recommendation, or favoring by the United States Government or the University of California. The views and opinions of authors expressed herein do not necessarily state or reflect those of the United States Government or the University of California, and shall not be used for advertising or product endorsement purposes.

This report has been reproduced directly from the best available copy.

Available to DOE and DOE contractors from the Office of Scientific and Technical Information

P.O. Box 62, Oak Ridge, TN 37831

Prices available from (615) 576-8401, FTS 626-8401

Available to the public from the

National Technical Information Service

U.S. Department of Commerce

5285 Port Royal Rd.,

Springfield, VA 22161 


\title{
Upgrading of Heavy Oil from the San Joaquin Valley of California by Aqueous Pyrolysis
}

\author{
John G. Reynolds, Ann M. Murray, Eric V. Nuxoll, and Glenn A. Fox \\ Lawrence Livermore National Laboratory \\ University of California \\ Livermore, CA 94551 \\ 510-422-6028, 510-423-4289, reynolds3@llnl.gov
}

\begin{abstract}
Midway Sunset crude oil and well-head oil were treated at elevated temperatures in a closed system with the presence of water. Mild to moderate upgrading, as measured by increase in API gravity, was observed at $400^{\circ} \mathrm{C}$ or above. Reduced pressure operation exhibited upgrading activity comparable to upgrading under normal aqueous pyrolysis conditions. Reduced pressure operation was obtained by the use of specific blending methods, a surfactant, and the proper amount of water. The use of additives provided additional upgrading. The best of the minimum set tested was Co(II) 2-ethylhexanoate. Fe(III) 2-ethylhexanoate also showed some activity under certain conditions.
\end{abstract}

\section{Introduction}

California is a major source of heavy crude oil. Approximately $650,000 \mathrm{bbl}$ of crude oil with API gravity of $20^{\circ}$ or less are produced daily, and 60 billion bbl are estimated in place (1). The value of this crude oil is governed by several factors. The pricing of San Joaquin valley (SJV) crude oils has been with reference to West Texas Intermediate adjusted for transportation costs. Until recently, Alaskan North Slope dictated much of the price differential between light and heavy oil. With the recent rescission of the export ban on ANS, the price structure has become unpredictable. In addition to this, the value can be linked to the availability of light oil in the SJV because the necessity of blending for transportation in existing pipelines. The anticipated sale by the Department of Energy of the Elk Hills field, the major source of light oil in the area, may cause further manipulation of the price oil heavy crude oils in the SJV.

Many of these value problems of heavy crude oil could be possibly circumvented if the material is upgraded at the well-head. Possible methods are traditional refining such as hydrotreating and hydroconversion. Other methods such as pyrolysis could also be applied. Initial applications (2) show that pyrolysis can increase API gravity (potentially increasing the price), decrease viscosity (facilitating pumpability and reducing necessity of blending for transportation), and reduce heteroatom content (aiding processability). 
Table 1. Selected Feed Property Comparisons of ANS, KR and MWSS Crude Oils

\begin{tabular}{|c|c|c|c|}
\hline Property & ANS & KR & MWSS \\
\hline Gravity, $^{\circ}$ API & 26.2 & 13.6 & 11.8 \\
\hline Sulfur, wt \% & 1.1 & 1.1 & 1.54 \\
\hline Viscosity@40 $90^{\circ} \mathrm{C}, \mathrm{cSt}$ & 14 & 1300 & na \\
\hline Viscosity@50ㄷ, cSt & 11 & 600 & na \\
\hline Pour Point, ${ }^{\circ} \mathrm{F}$ & 15 & 20 & 60 \\
\hline Acid, equivalents $\mathrm{KOH} / \mathrm{g}$ & 0.1 & 4.0 & 4.3 \\
\hline \multicolumn{4}{|l|}{ Boiling Range Yields, vol \% } \\
\hline $\mathrm{C} 4-$ & 0.9 & 0.0 & 0.0 \\
\hline Light Gasoline & 3.5 & 0.0 & 0.0 \\
\hline Light Naphtha & 3.5 & 0.2 & 0.0 \\
\hline Heavy Naphtha & 7.3 & 1.5 & 1.0 \\
\hline Kerosene & 9.6 & 6.0 & 6.0 \\
\hline Atmospheric Gas Oil & 16.2 & 15.3 & 11.7 \\
\hline Light Vacuum Gas Oil & 15.1 & 15.6 & 15.2 \\
\hline Heavy Vacuum Gas Oil & 14.8 & 23.9 & 22.2 \\
\hline Vacuum Residuum & 24 & 23.9 & 43.7 \\
\hline \multicolumn{4}{|l|}{ Residuum } \\
\hline Gravity, ${ }^{\circ} \mathrm{API}$ & 7.8 & 5.8 & 4.6 \\
\hline Sulfur, wt $\%$ & 2.5 & 1.3 & 2.0 \\
\hline Nitrogen, wt $\%$ & 0.7 & 1.4 & $1: 0$ \\
\hline Metals $(\mathrm{Fe}+\mathrm{Ni}+\mathrm{V})$ & 145 & 295 & 333 \\
\hline
\end{tabular}

Table 1 compares selected properties of two SJV feeds, Kern River (KR) and Midway Sunset (MWSS) crude oils with ANS. KR field is east of Bakersfield area in the SJV. MWSS field is south of Taft and the oils are from secondary production by steam recovery. The ANS is a better feed having a much higher gravity, lower viscosity, and a boiling point distribution towards lighter, more volatile materials than both KR and MWSS. Sulfur concentrations are not too much different, while the metals (as seen concentrated in the residuum portion), are much higher in the SJV feeds. Clearly, some sort of pretreatment or upgrading would be necessary to make the SJV feeds comparable to ANS.

Aqueous pyrolysis is the thermal treatment of materials in the presence of water in a closed system. The method has been primarily utilized in geochemical studies (3) of source rocks, but also has been utilized to upgrade heavy oils (2). The reaction conditions range from low temperature and long reaction times (geochemistry) to high temperatures and short reaction times (process chemistry). Water is thought to be somehow involved in hydrogen transfer, although the mechanisms for this are not clear (4). Presented here are the results 
of our initial studies on the aqueous upgrading of selected feeds from SJV using both a gold bag and a stainless steel autoclaves.

\section{Experimental}

Feeds included MWSS crude oil (API gravity $-11.5^{\circ}$ ), which has been through the primary and secondary separators $\left(1.0 \mathrm{wt} \% \mathrm{H}_{2} \mathrm{O}\right)$ at the production field, and MWSS well-head oil (API gravity $-13.6^{\circ}$ ), which was taken directly at the well head. Originally, this oil contained $30 \mathrm{wt} \% \mathrm{H}_{2} \mathrm{O}$. However, after sitting, the emulsion separated naturally and was found to contain 1.25 wt $\% \mathrm{H}_{2} \mathrm{O}$ (DeanStark water trap, toluene azeotrope). This water content was included when calculating water content for the aqueous pyrolysis experiments.

The following chemicals were purchased from the follow companies: $\mathrm{CoCl}_{2}$ and 2-ethylhexanoic acid from Aldrich Chemical Company (Milwaukee WI); $\mathrm{Ni}\left(\mathrm{NO}_{3}\right)_{2}$ from Mallinckrodt (Paris, $\mathrm{KY}$ ); $\mathrm{CuCl}_{2}, \mathrm{CaCl}_{2}$ and $\mathrm{FeCl}_{3} \bullet 6 \mathrm{H}_{2} \mathrm{O}$ from Baker (Phillipsburg NJ); $\mathrm{Zn}\left(\mathrm{NO}_{3}\right)_{2}$ from Morton Thiokol, Inc., (Danvers $\mathrm{MA}$ ); $\mathrm{NaMoO}_{3}$, from Fisher Scientific (Fair Lawn NJ); Ca naphthenate and naphthenic acid from Pfaltz \& Bauer (Waterbury .CT); hexane as B \& J Brand from Baxter Scientific. Infrared measurements were taken on a Nicolet model Impact $400 \mathrm{D}$ Fourier Transform Instrument (Madison WI).
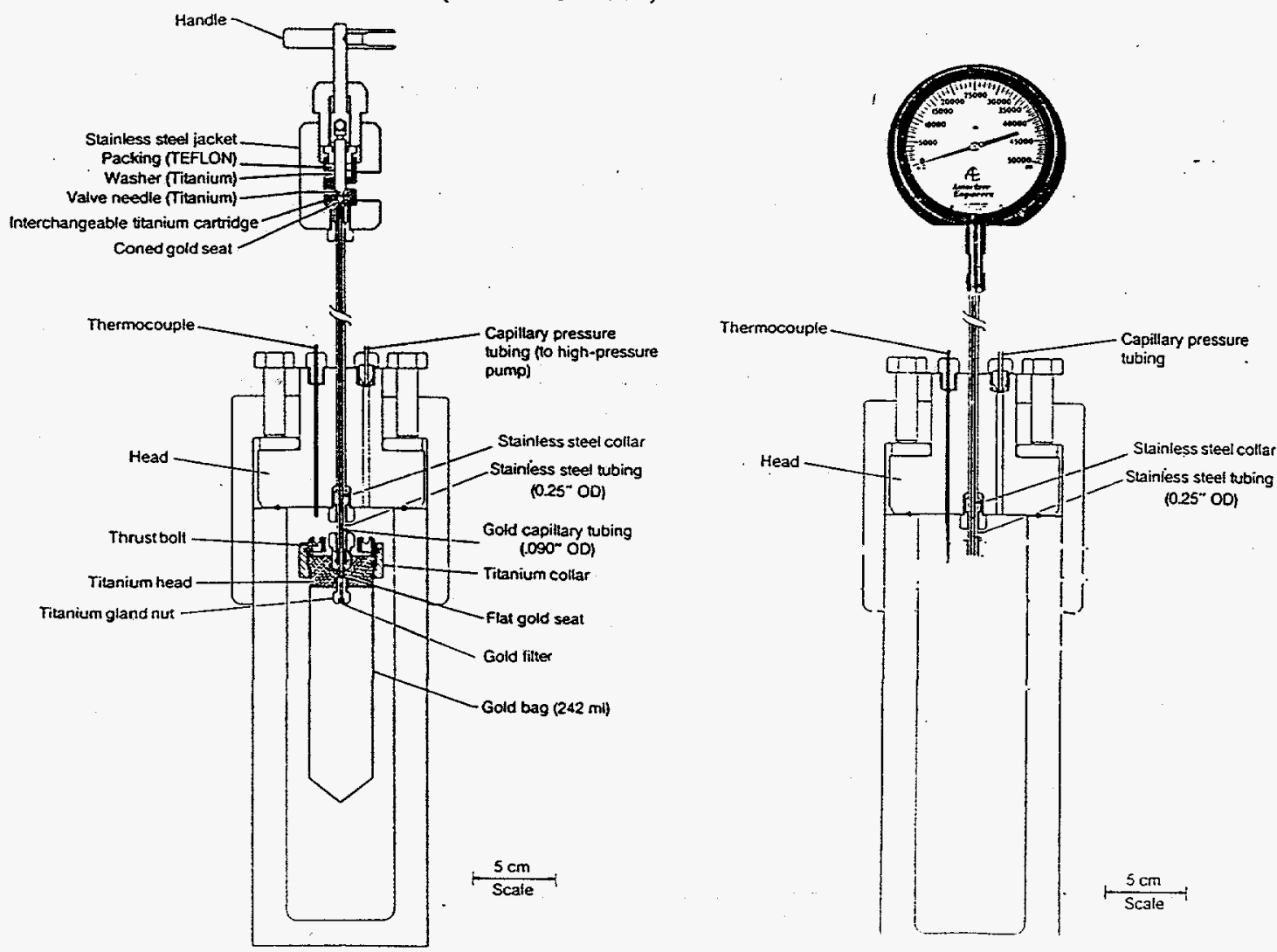

Figure 1. Diagrams of Gold Bag and Stainless Steel Autoclaves 
Autoclave Experiments. Autoclaves were NATL BD 1251, manufactured by Autodave Engineers (Erie PA) and HIPGC13 manufactured by High Pressure Equipment, Inc. (Erie PA). Two types of reactors, gold bag and stainless steel, were used. Figure 1 shows diagrams of both. The gold-bag reactors are flexible and are surrounded by water. This water is used to maintain constant pressure on the system throughout the runs. The plumbing was also designed for gas and oil sampling at any time. The volume of the reactor was roughly $250 \mathrm{ml}$. The stainless-steel reactors were simplified versions of the gold-bag reactor with the gold bag removed, and the gas-sampling system replaced with a standard gauge. These reactors were constant volume with the pressure starting at atmospheric at the beginning of the run. Gas sampling was done only when the system had returned to room temperature. Volumes of stainless-steel reactors were $1050 \pm 5$ $\mathrm{ml}$ and $784 \pm 2 \mathrm{ml}$.

Feed mixtures used in the stainless-steel reactors were prepared by mixing approximately $400 \mathrm{~g}$ of oil with the appropriate amount of water, catalyst, and surfactant in either a Blender (Osterizer brand) or with a small paint mixer attached to a power drill. Emulsions were prepared fresh for each run, even though mixtures with surfactant were observed to stay emulsified for at least several weeks.

Reactors were heated using the maximum temperature ramp allowed for the furnaces. Typically, the heat up time was 4 to 6 hours before $350^{\circ} \mathrm{C}$ was reached. The reactors were then held at the designated reaction temperature for the allotted reaction time and then cooled overnight. Reactions in the gold-bag reactors were not rocked while all reactions in the stainless-steel reactors were rocked during the entire run.

Analysis. After the reactors were cooled below $40^{\circ} \mathrm{C}$, the system pressure was recorded and a gas sample was taken. The gas sample was analyzed by gas analysis mass spectrometry for light hydrocarbon and noncondensible gases. Air leaks in the sampling system were adjusted using $\mathrm{Ar}$ concentrations as an internal standard. The liquid contents were poured from the reactor into centrifuge tubes, and the water was separated from the oil by centrifugation (Fisher Scientific Marathon 6K Centrifuge). The insolubles remained in the reactor and were either scraped out or washed out with toluene and isolated by filtration. These insolubles were considered coke. Mass balances were performed whenever possible. In several experiments, insolubles were not detected. In addition, the insolubles were not always thoroughly washed with solvent, so the total value generally included some product oil. API gravities were measured on the product oil using a Mettler DA-30 densiometer (Danberry, MA).

Catalysts. The 2-ethylhexanoate (2-EtH) and naphthenate catalysts were synthesized from the reaction of the metal chloride with in situ formed potassium 2-EtH or $\mathrm{Na}$ naphthenate in $\mathrm{H}_{2} \mathrm{O}$. The solution was extracted with 
hexane for the $\mathrm{Fe}$ (III) salt and with $\mathrm{CH}_{2} \mathrm{Cl}_{2}$ for the $\mathrm{Co}$ (II) and $\mathrm{Ca}$ (II) salts. The solvent was removed by rota-evaporation to isolate the catalyst. FTIR was used to verify the reaction product, and no further steps were taken for purification. The other catalysts were used as received.

Results

Table 2. Aqueous Pyrolysis of MWSS Crude Oil ${ }^{a}$ using Gold-Bag Reactors

\begin{tabular}{lcc}
\hline Conditions & Gravity, ${ }^{\circ} \mathrm{API}$ & Mass Balance, $\%^{\mathrm{b}}$ \\
\hline $400^{\circ} \mathrm{C}, 30 \mathrm{MPa}, 3 \mathrm{~h}$ & 13.9 & na \\
$400^{\circ} \mathrm{C}, 30 \mathrm{MPa}, 1 \mathrm{~h}$ & 14.4 & na \\
$400^{\circ} \mathrm{C}, 30 \mathrm{MPa}, 1 \mathrm{~h}$ & 13.4 & na \\
$425^{\circ} \mathrm{C}, 30 \mathrm{MPa}, 1 \mathrm{~h}$ & 17.9 & 91 \\
$400^{\circ} \mathrm{C}, 30 \mathrm{MPa}, 1 \mathrm{~h}, \mathrm{FeCl}_{3}$ & 14.5 & 62 \\
$342^{\circ} \mathrm{C}, 14.4 \mathrm{MPa}, 3 \mathrm{~h}$ & 11.7 & 89 \\
$335^{\circ} \mathrm{C}, 15.0 \mathrm{MPa}, 3 \mathrm{~h}, \mathrm{Fe}$ naphthenate & 13.1 & 98 \\
$340^{\circ} \mathrm{C}, 20 \mathrm{MPa}, 3 \mathrm{~h}, \mathrm{Ca}$ naphthenate & 11.7 & 96 \\
\hline
\end{tabular}

a. $11.5^{\circ}$ API Gravity; b. gas + oil + solids

Gold Bag Experiments. Table 2 shows the results from the upgrading of MWSS crude oil in the gold-bag reactor. These runs were performed to establish baseline results and evaluate literature conditions. The first three runs were performed duplicating conditions from the patents of McCollum and Quick (2) for the upgrading of an unspecified tar sand bitumen of $12.2^{\circ}$ API. The projected gravity change for MWSS crude oil (calculated from the gravity differential of the tar sand bitumen and the processed products from the patents) for the first three entries in Table 2 is $19.9^{\circ}$. Obviously, the gold bag runs do not reach anywhere near the activity that the patent results suggest. The reason is possibly due to the Castaloy $C$ autoclaves used for the runs in the patent provided some catalytic activity, while the gold bags under the same conditions are essentially inert, or the true reaction temperatures are not comparable.

Raising the temperature $25^{\circ} \mathrm{C}$ shows more activity, consistent with the behavior in the patent literature which shows a moderate temperature effect. Adding $\mathrm{FeCl}_{3}$ shows little increased activity over the baseline.

For the bottom three entries in Table 2, much lower temperatures and pressures were selected. These were temperatures at which the reactor could be operated at the listed pressure in which the water stayed in the liquid phase. The $342^{\circ} \mathrm{C}$ run shows without any additive, no upgrading is observed. The run using $\mathrm{Fe}$ (III) naphthenate shows possibly some upgrading, where the API gravity appears slightly higher. Using $\mathrm{Ca}$ (II) naphthenate at about the same temperature shows no upgrading. 
Low Severity Experiments. Several runs were performed using the stainless-steel autoclaves at milder conditions. In these cases, the temperatures were selected for maximum severity conditions while still keeping the water in the liquid phase. Generally, the pressure was chosen as the target parameter, and the temperature was adjusted until the pressure was reached.

Table 3. Aqueous Pyrolysis using a Stainless Steel Reactor - Low Severity

\begin{tabular}{lcc}
\hline Conditions & Gravity, ${ }^{\circ} \mathrm{API}$ & Mass Balance, $\%^{\mathrm{a}}$ \\
\hline $252^{\circ} \mathrm{C}, 4 \mathrm{MPa}, 3 \mathrm{~h}, 75 \% \mathrm{H}_{2} \mathrm{O}$ & $11.5^{\mathrm{b}}$ & na \\
$259^{\circ} \mathrm{C}, 4 \mathrm{MPa}, 12 \mathrm{~h}, 75 \% \mathrm{H}_{2} \mathrm{O}$ & $11.5^{\mathrm{b}}$ & na \\
$258^{\circ} \mathrm{C}, 4 \mathrm{MPa}, 12 \mathrm{~h}, 75 \% \mathrm{H}_{2} \mathrm{O}$, Fe naphthenate & $11.4^{\mathrm{b}}$ & 94 \\
$258^{\circ} \mathrm{C}, 4 \mathrm{MPa}, 12 \mathrm{~h}, 30 \% \mathrm{H}_{2} \mathrm{O}^{\mathrm{e}}$ & $13.3^{\mathrm{c}}$ & 92 \\
$258^{\circ} \mathrm{C}, 3 \mathrm{MPa}, 12 \mathrm{~h}, 30 \% \mathrm{H}_{2} \mathrm{O}^{\mathrm{e}}$ & $13.5^{\mathrm{c}}$ & 95 \\
$258^{\circ} \mathrm{C}, 4 \mathrm{MPa}, 12 \mathrm{~h}, 30 \% \mathrm{H}_{2} \mathrm{O}^{\mathrm{e}}$, Fe naphthenate & $13.2^{\mathrm{c}}$ & 94 \\
$254^{\circ} \mathrm{C}, 3 \mathrm{MPa}, 12 \mathrm{~h}, 30 \% \mathrm{H}_{2} \mathrm{O}^{\mathrm{e}}$, Fe naphthenate & $13.8^{\mathrm{c}}$ & 91 \\
$258^{\circ} \mathrm{C}, 4.5 \mathrm{MPa}, 12 \mathrm{~h}, 30 \%$ pumping water $^{\mathrm{d}}$ & $13.3^{\mathrm{c}}$ & 65 \\
$257^{\circ} \mathrm{C}, 4.5 \mathrm{MPa}, 12 \mathrm{~h}, 30 \% \mathrm{H}_{2} \mathrm{O}^{\mathrm{e}}$, reblended & $13.1^{\mathrm{c}}$ & na \\
$340^{\circ} \mathrm{C}, 15 \mathrm{MPa}, 17 \mathrm{~h}, 30 \% \mathrm{H}_{2} \mathrm{O}^{\mathrm{e}}$, Fe naphthenate & $14.5^{\mathrm{c}}$ & na \\
\hline
\end{tabular}

a. gas + oil + solids; b. MWSS crude oil feed $-11.5^{\circ} ;$ c. MWSS well-head oil feed $13.5^{\circ}$; d. water from well head; e. MWSS well-head oil reblended to incorporate original water $(30 \mathrm{wt} \%)$.

Table 3 shows the results. The first three entries were runs using the MWSS crude oil, while the other entries were using MWSS well-head oil. The crude oil runs exhibited no appreciable change in the API gravity, even when the reaction time was several hours, and the water loading was very high. Addition of $\mathrm{Fe}$ naphthenate caused no change.

The runs with the MWSS well-head oil also showed no upgrading at run temperatures around $255^{\circ} \mathrm{C}$, with or without additives. Note also the pumping water (water retrieved from the well head) had no effect at this temperature. When the temperature was raised to $340^{\circ} \mathrm{C}$ and $\mathrm{Fe}$ naphthenate was used as an additive, a little upgrading may be evident after $17 \mathrm{~h}$, which is consistent with the results observed in Table 2. However, to operate at that temperature, the pressure had to be much higher.

Reduced Pressure Experiments. Figure 2 shows the behavior of the pressure measured in the stainless-steel reactor with MWSS well-head oil mixed with water. The reactor temperature was raised to a maximum temperature of $348^{\circ} \mathrm{C}$, held for $30 \mathrm{~min}$, and then allowed to cool to room temperature. Three feeds were used -- pure water; a 6\% water and MWSS well-head oil mixture; and a $6 \%$ water, MWSS well-head oil, and surfactant mixture.

The pure water curve shows the highest pressure of all three, reaching approximately $16.2 \mathrm{MPa}$ (2350 psig) at the maximum temperature. The MWSS 
well-head oil mixture reached approximately $10.5 \mathrm{MPa}$ (1523 psig) at maximum temperature, while the MWSS well-head oil with surfactant only reached approximately $8 \mathrm{MPa}(1160 \mathrm{psig})$. The reasons for this reduced pressure

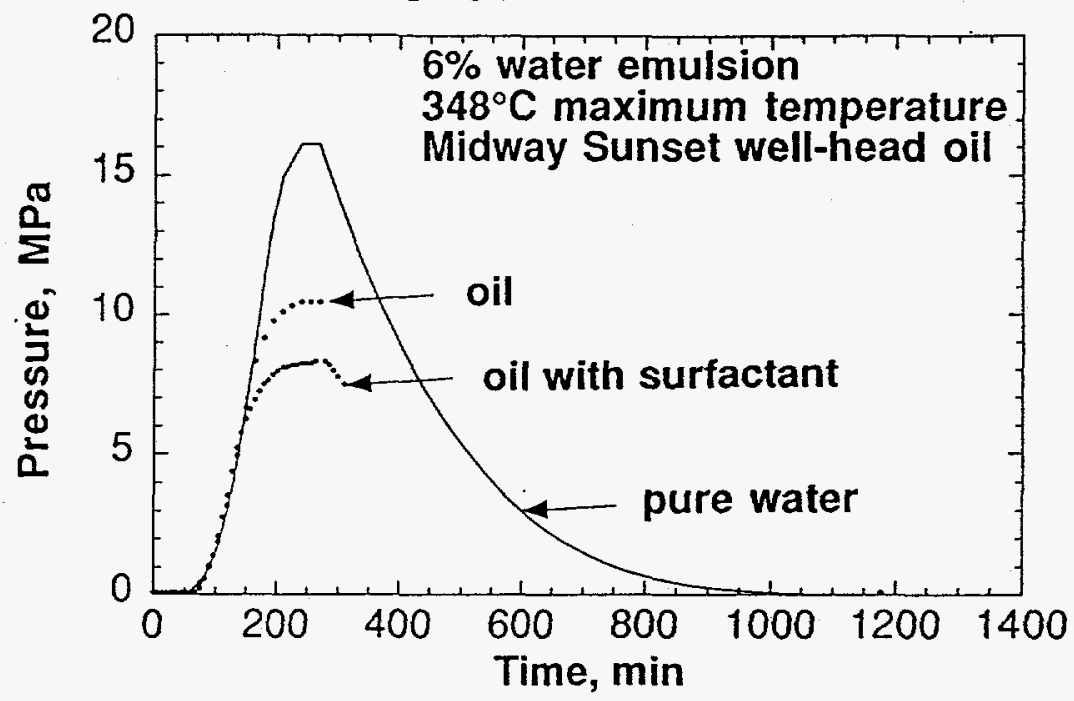

Figure 2. Pressure behavior of MWSS well-head oil with and without surfactant.

behavior of the water-oil mixtures will be described elsewhere, but is attributed to increasing solubility of water in oil with increasing temperature. This behavior has been seen with higher and lower concentration water-oil mixtures, from 3 to $12 \mathrm{wt} \%$ water, also. The interpretation of the behavior is that the emulsified water can either dissolve in the oil or become free-phase water. As the temperature of the mixture increases, the solubility of the oil increases. Water miscibility with the oil depends up the dispersion, which is assisted by the surfactant. More free-phase water will form if the water is not finely dispersed or emulsified, and the pressure behavior of the reactor will be dominated by the free-phase water. If the emulsion is properly prepared, the pressure will remain substantially lower than expected for free-phase water at the same temperature.

Table 4 shows a series of experiments demonstrating the utility of this phenomenon. The first entry shows the upgrading of MWSS well-head oil combined with water and surfactant to give a $6 \mathrm{wt} \%$ water mixture. Some upgrading is observed as measured by API gravity. A small amount of coke was generated and the pressure was $11 \mathrm{MPa}(1600 \mathrm{psig})$. The next entry shows the upgrading of MWSS well-head oil with only Co(II)2EtH (1.25 wt \% $\mathrm{H}_{2} \mathrm{O}$ ). Much more upgrading is observed because of the catalyst. The pressure is much lower and the coke formation is much higher because of the small amount of water. The third entry shows upgrading of MWSS well-head oil with a much higher concentration of water. The API gravity shows upgrading is the same as in the first entry without additive. The reason for the loss of additive effect is unknown, but may reflect the overwhelming effect of the high concentration of water. High $\mathrm{H}_{2} \mathrm{O}$ concentration also is reflected in the very high pressure compared to the other runs. Free-phase water is dominating the pressure. Coke 
formation is comparable to the other cases with water. The fourth entry shows the effects of having all the components, surfactant, additive, 6 wt $\%$ water, all blended in an emulsified form. The upgrading seen in the additive only case is obtained. However, the pressure is much lower than in the high water case, and the coke formation is greatly lower than the additive only case. The final entry is the same is the experiment just above, accept none of the components were blended before the start of the reaction. Clearly, blending is necessary for all these components to work synergistically.

Table 4. Aqueous Upgrading of MWSS Well-Head Oil with $\mathrm{Co}$ (II)2EtH

\begin{tabular}{|c|c|c|c|c|c|c|}
\hline Catalyst $^{\mathrm{a}}$ & $\begin{array}{l}\text { Total } \\
\% \mathrm{H}_{2} \mathrm{O}^{\mathrm{g}}\end{array}$ & Temp., ${ }^{\circ} \mathrm{C}^{\mathrm{b}}$ & $\begin{array}{l}\text { API } \\
\text { Gravityc }^{c}\end{array}$ & $\begin{array}{l}\mathrm{P}, \mathrm{MPa} \\
(\text { psig) }\end{array}$ & Coke, wt $\%^{\mathrm{e}}$ & Surfactant $f^{f}$ \\
\hline no & $\overline{6}$ & 401 & $16.9^{\circ}$ & $11.0(1600)$ & 1 & no \\
\hline yes & 1.25 & 403 & $19.9^{\circ}$ & $5.5(800)$ & 6.3 & no \\
\hline yes & 30 & 405 & $16.8^{\circ}$ & $280.7(4070)$ & 2.7 & no \\
\hline yes & 6 & 403 & $19.3^{\circ}$ & $12.0(1740)$ & 2.9 & yes \\
\hline yes & 6 & 403 & $17.7^{\circ}$ & $11.2(1630)$ & 1 & yes \\
\hline
\end{tabular}

a. 1 wt \% Co(II)ethylhexanoate; b. reaction time 60 min.; c. MWSS well-head oil -. $13.6^{\circ} \mathrm{API}$; d. maximum pressure at reaction temperature - residual pressure at room temperature after reaction; e. wt $\%$ of feed; $f$. $1 \mathrm{~g} / 500 \mathrm{~g}$ of charge; $\mathrm{g}$. includes $1.25 \mathrm{wt} \%$ water occurring in well-head oil.

Table 5. Aqueous Upgrading of MWSS Well-Head Oil with Fe(III)2EtH

\begin{tabular}{lcccccc}
\hline Catalyst $^{\mathrm{a}}$ & $\begin{array}{l}\text { Total } \\
\% \mathrm{H}_{2} \mathrm{O}^{\mathrm{h}}\end{array}$ & Temp., $^{\circ} \mathrm{C}^{\mathrm{b}}$ & $\begin{array}{c}\text { API } \\
\text { Gravity }\end{array}$ & $\begin{array}{l}\mathrm{P}, \mathrm{MPa} \\
(\mathrm{psig})^{\mathrm{d}}\end{array}$ & Coke, wt\% & Surfactant \\
\hline $1 \mathrm{wt} \%$ & 6 & $402^{\mathrm{b}}$ & $16.8^{\circ}$ & $11.2(1620)$ & $\mathrm{tr}$ & yes \\
$1 \mathrm{wt} \%$ & 6 & $412^{\mathrm{b}}$ & $17.5^{\circ}$ & $12.9(1870)$ & na & yes \\
$0.25 \mathrm{wt} \%$ & 6 & $405^{\mathrm{b}}$ & $17.9^{\circ}$ & $11.8(1715)$ & 1 & yes \\
$0.25 \mathrm{wt} \%$ & 30 & $402^{\mathrm{b}}$ & $17.3^{\circ}$ & $27.6(4000)$ & na & no \\
$0.25 \mathrm{wt} \%$ & 6 & $429^{\mathrm{g}}$ & $22.0^{\circ}$ & $16.4(2380)$ & 5.3 & yes \\
\hline
\end{tabular}

a. $1 \mathrm{wt} \% \mathrm{Fe}$ (III) 2-ethylhexanoate; b. reaction time $60 \mathrm{~min}$; c. MWSS well-head oil $13.6^{\circ} \mathrm{API} ; \mathrm{d}$. maximum pressure at reaction temperature - residual pressure at room temperature after reaction; e. wt $\%$ of feed; $\mathrm{f} .1 \mathrm{~g} / 500 \mathrm{~g}$ of charge; $\mathrm{g}$. reaction time 30 min; $h$. includes $1.25 \mathrm{wt} \%$ water occurring in well-head oil.

Table 5 shows the upgrading of MWSS well-head oil, water and Fe(III)2EtH as an additive at two concentrations. The first entry shows Fe(III) $2 \mathrm{EtH}$ at $\mathrm{I}$ wt \% is not 
as an effective additive as $\mathrm{Co}(\mathrm{II}) 2 \mathrm{EtH}$ at $1 \mathrm{wt} \%$. However, pressure behavior is about the same. In all $6 \mathrm{wt} \%$ water cases, the pressure is much lower than expected for free-phase water, consistent with Figure 2 and Table 4. The $30 \mathrm{wt} \%$ water experiment yields the same high pressure as the $30 \mathrm{wt} \%$ water case in Table 4. Note the coke formation is low in these experiments, partly due to the presence of water, and partly due to the additive not having nearly the effect as the $\mathrm{Co}$ (II) $2 \mathrm{EtH}$ additive. The reaction temperature was also brought to $429^{\circ} \mathrm{C}$ in one experiment and held for $30 \mathrm{~min}$. The API gravity and coke formation reflect the higher upgrading. The pressure is around 2000 psig.

Table 6. Aqueous Upgrading of MWSS Well-Head Oil with $\mathrm{NaMoO}_{3}$

\begin{tabular}{|c|c|c|c|c|c|c|}
\hline Catalyst $^{a}$ & $\begin{array}{l}\text { Total } \\
\% \mathrm{H}_{2} \mathrm{O}^{\mathrm{h}}\end{array}$ & Temp.,${ }^{\circ} \mathrm{C}^{\mathrm{b}}$ & $\begin{array}{l}\text { API } \\
\text { Gravity }^{c}\end{array}$ & $\begin{array}{l}\text { P, MPa } \\
\text { (psig) }^{d}\end{array}$ & Coke, wt\% ${ }^{\mathrm{e}}$ & Surfactant \\
\hline $1 \mathrm{wt} \%$ & 6 & $405^{b}$ & $16.9^{\circ}$ & $11.5(1670)$ & 1.1 & yes \\
\hline $0.25 \mathrm{wt} \%$ & 6 & $403^{b}$ & $16.9^{\circ}$ & $11.2(1625)$ & 2 & yes \\
\hline 0.25 wt $\%$ & 6 & $428^{g}$ & $18.3^{\circ}$ & $17.2(2490)$ & 14 & yes \\
\hline
\end{tabular}

a. $\mathrm{NaMoO}_{3}$; b. reaction time 60 min.; c. MWSS well-head oil - $13.6^{\circ}$ API; d. maximum pressure at reaction temperature - residual pressure at room temperature after reaction; $\mathrm{e}$. wt $\%$ of feed; f. $1 \mathrm{~g} / 500 \mathrm{~g}$ of charge; $\mathrm{g}$. reaction time $30 \mathrm{~min}$; h. includes $1.25 \mathrm{wt} \%$ water occurring in well-head oil.

Table 7. Aqueous Upgrading of MWSS Well-Head Oil with Miscellaneous Additives

\begin{tabular}{|c|c|c|c|c|c|c|}
\hline Catalyst $^{a}$ & $\begin{array}{l}\text { Total } \\
\% \mathrm{H}_{2} \mathrm{O}^{\mathrm{g}}\end{array}$ & Temp., ${ }^{\circ} \mathrm{C}^{\mathrm{b}}$ & $\begin{array}{l}\text { API } \\
\text { Gravity }^{\circ}\end{array}$ & $\begin{array}{l}\mathrm{P}, \mathrm{MPa} \\
\text { (psig) }^{\mathrm{d}}\end{array}$ & Coke, wt\% ${ }^{\mathrm{e}}$ & Surfactant \\
\hline $\mathrm{CuCl}_{2}^{\mathrm{h}}$ & 6 & $407^{b}$ & $19.3^{\circ}$ & $13.0(1890)$ & 1 & yes \\
\hline $\mathrm{Zn}\left(\mathrm{NO}_{3}\right)_{2}{ }^{\mathrm{h}}$ & 6 & $360^{b}$ & $13.7^{\circ}$ & $9.2(1340)$ & $\operatorname{tr}$ & yes \\
\hline $\left.\mathrm{Zn}(\mathrm{NO})_{3}\right)_{2}{ }^{\mathrm{h}}$ & 6 & $385^{\mathrm{b}}$ & $15.6^{\circ}$ & $10.3(1490)$ & $\operatorname{tr}$ & yes \\
\hline $\mathrm{CoCl}_{2}{ }^{\mathrm{i}}$ & 6 & $350^{b}$ & $14.2^{\circ}$ & $7.6(1100)$ & na & yes \\
\hline $\mathrm{Ni}\left(\mathrm{NO}_{3}\right)_{2}{ }^{\mathrm{i}}$ & 6 & $350^{b}$ & $13.7^{\circ}$ & $8.3(1200)$ & na & yes \\
\hline
\end{tabular}

a. $1 \mathrm{wt} \%$; b. reaction time $60 \mathrm{~min}$; c. MWSS well-head oil - $13.6^{\circ}$ API; d. maximum pressure at reaction temperature - residual pressure at room temperature after reaction; $\mathrm{e}$. wt $\%$ of feed; $\mathrm{f}$. $1 \mathrm{~g} / 500 \mathrm{~g}$ of charge; $\mathrm{g}$. includes $1.25 \mathrm{wt} \%$ water occurring in well-head oil; h. catalyst dissolved in $\mathrm{H}_{2} \mathrm{O}$ prior to blending; i. catalyst not dissolved in $\mathrm{H}_{2} \mathrm{O}$ prior to blending.

Table 6 shows the upgrading of MWSS well-head oil with water using $\mathrm{NaMoO}_{3}$ as an additive at two concentrations. In these cases, the $\mathrm{NaMoO}_{3}$ was not dissolved in the water before blending. The API gravity shows essentially baseline upgrading for the 1 and $0.25 \mathrm{wt} \%$ cases at $\sim 400^{\circ} \mathrm{C}$. However, again the 
pressure comparable to the similar-condition runs in Table 4 and 5. The coke formation is also low, but probably a result of the minimal upgrading and the presence of the water. The last entry shows the reaction temperature was raised to $428^{\circ} \mathrm{C}$ and held there for $30 \mathrm{~min}$. Again, increased upgrading activity is seen, similar to the $429^{\circ} \mathrm{C}$ case in Table 5. The pressure was also comparable.

Table 7 shows the upgrading of MWSS well-head oil with water and various additives at different temperatures. $\mathrm{CuCl}_{2}$ showed similar activity to $\mathrm{Co}(\mathrm{II}) 2 \mathrm{EtH}$ as shown in Table 4. The pressures of these runs were also similar. The experiments with the other additives did not show much upgrading. However, the temperatures were in the low range for any cracking to occur. . The water pressures were also low, consistent with the behavior in Figure 2.

\section{Discussion}

The results in the various tables and Figure 2 provide useful information for upgrading of heavy crude oils by aqueous pyrolysis. The proper blending of water with the oil before heating can reduce the operating pressures substantially. Economic evaluation of this aqueous pyrolysis system shows the pressure vessel costs increase dramatically when the pressure rating increases (6). To operate at $\sim 27.5 \mathrm{MPa}$ ( $4000 \mathrm{psig}$ ), which would be necessary under freephase water at the temperatures needed for this type of upgrading, would not be commercially feasible at this time. However, blending water and oil properly, with surfactant and reduced water content, lowers this pressure substantially, substantially reducing pressure vessel costs. In addition, the lower pressure at higher temperature allows reaching effective upgrading temperatures at more reasonable capital equipment expense. Use of the appropriate catalyst, also mixed properly, allows for more upgrading chemistry to occur at these conditions.

\section{Conclusions}

MWSS crude oil and MWSS well-head oil were effectively upgrading using water under high pressure. The use of proper blending techniques, proper amount of water, and a surfactant allowed upgrading at substantially lower pressures than normally seen for aqueous pyrolysis. Of the additives screened, $\mathrm{Co}$ (II) $2 \mathrm{EtH}$ yielded the best performance, although the conditions have not been optimized for any of the additives.

\section{Acknowledgments}

We thank M. Rashid Khan of Texaco for the surfactant, Kevin Knauss of LLNL for autoclave advise, and Kenneth J. King of LLNL for use of the densiometer. This work was performed under the auspices of the U. S. Department of Energy by the Lawrence Livermore National Laboratory under Contract No. W-7405ENG-48. 


\section{References}

1. D. K. Olsen, U. S. DOE report DE93000153 (1993).

2. J. D. McCollum and L. M. Quick, U.S. Patent 3960706 (1976); A. K. S. Murthy, K. M. Patel, and A. Y. Bekker, The Third Unitar/UNDP International Conference on Heavy Crude and Tar Sand, Chapter 122, 1291-1296 (1985

3. M. D. Lewin, ACS Div. Fuel Chem., Preprints, 37(4), 1545-1547 (1992).

4. D. S. Ross, I. Jayaweera, and S. Hoogwater, ACS Div. Petrol. Chem., Preprints, 353-355 (1994).

5. C. B. Thorsness, W. A. Hall, and J. G. Reynolds, report in preparation.

6. C. B. Thorsness, report in preparation. 


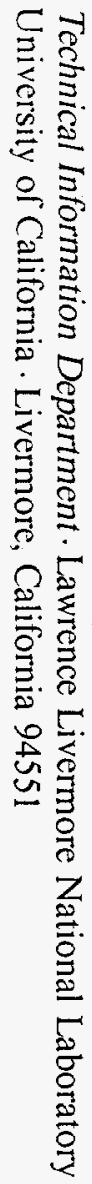

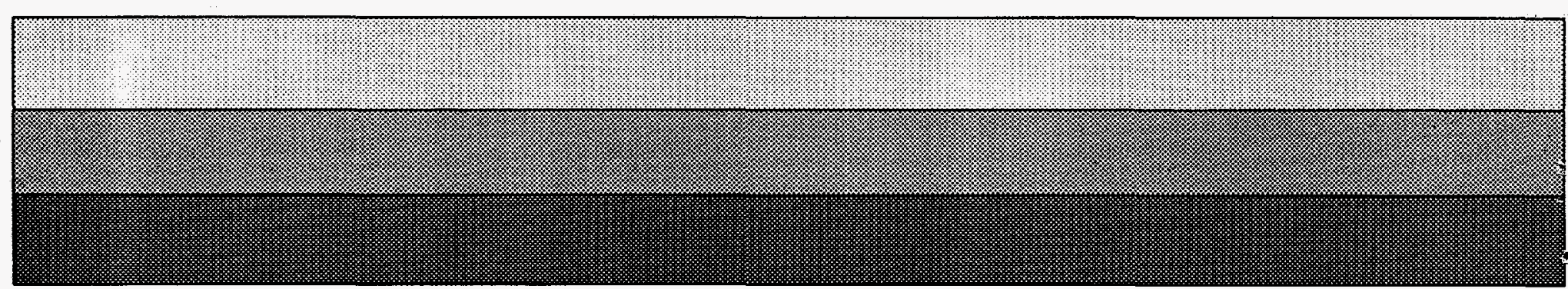

